\title{
Considerations in the Neuroscience of Adolescent Brain Development: What Clinicians Can Use
}

\author{
Barbara D'Amato* \\ The Center for Modern Psychoanalytic Studies and the New York Graduate School of Psychoanalysis, US
}

\begin{abstract}
Neuroscience findings suggest brain immaturity and the proliferation of neurons in the frontal cortex at puberty may be significant factors affecting adolescent behaviors. The author considers these findings essential to bolster the analyst's position to not act, in light of the impulses treating such cases can arouse. Clinical examples illustrate.
\end{abstract}

Keywords: Neuroscience of adolescence, Brain development, Separation, Clinicians, Adolescent therapy

There is nothing either good or bad, but thinking makes it so. (Shakespeare, Hamlet)

\section{Introduction}

Adolescence is a developmental period of turbulence. As teenagers are unconsciously attempting to separate from their families they frequently engage in oppositional and even bizarre behaviors. Neither the child, nor, the families understand the behaviors, and, both become regressed within a matrix of discord. Often, the situation deteriorates until the family seeks professional help. Throughout my years of clinical work with, and supervision of adolescent cases, I have learned there are a few analytic tenets to follow. To a large degree, silent containment of the adolescent's emotional storm, and, putting as much as possible into words, is the first task. Perhaps, more importantly, is the analyst's ongoing relationship with the adolescent's parents. Providing acceptance of parental misery concerning their son's or daughter's erratic moods and actions, along with continuous attempts at normalizing these alterations in behaviors, through regular parent sessions, is crucial.
Neuroscience studies have contributed important research that makes this process more tangible and perhaps even concrete for parents and clinicians alike. Zellner \& Olds ${ }^{1}$ attest to a need for more collaboration between mental health clinicians and neuroscientists in their editorial to volume 18 of Neuro-Psychoanalysis. In the face of the adolescent patient's impulsive action, and the subsequent impulsive responses of their family, this data can relieve some of the practitioner's tendency to also engage in action. Action becomes the primary resistance for clinicians to resolve when treating teens. Neuroscience findings can normalize contrary, out-of-control teenage behaviors and fortify the analyst in resisting powerful pressures from parents to control the child. Volkow \& $\mathrm{Koob}^{2}$ are currently conducting a longitudinal study of teens - known as the Adolescent Brain Cognitive Development Study - using brain imaging to evaluate multiple variables on the formation of the adolescent brain. Their comprehensive findings will hopefully shed further light on

\begin{tabular}{|l|l|}
\hline \hline Quick Response Code: & *Corresponding author: Barbara D'Amato, 6735 Ridge Boulevard, US \\
Received: 26 August, 2021 & Published: 10 September, 2021 \\
\hline & Citation: D'Amato B. Considerations in the Neuroscience of Adolescent Brain Development: \\
\hline
\end{tabular}


factors that mitigate teenage development and deportment. This paper describes some of the research that can be grounding for analysts, when confronted by the madness of the teen/family constellation. Several clinical vignettes will demonstrate the particular link that appears to exist between neuroscience research findings and the treatment of adolescents. Rather than through any specific verbatim interventions, the paper illustrates a gestalt of emotional communications conveyed to patients and their families. I have found the most important intervention to be that of inaction, accompanied by repetitive urging to put everything into words.

\section{Beginning with Freud}

A long history of psychoanalytic treatment with children and adolescents began with Freud's ${ }^{3}$ case of Little Hans. Many other psychoanalysts from Freud through the present day ${ }^{3-11}$ have made significant contributions to the field of child analysis. Neuroscience findings ${ }^{12,13}$ suggest that brain development has a notable impact on adolescent behavior. The conclusions in that field may be of substantial interest to clinicians working with teens and may enhance our understanding of the cases we treat.

Following the tradition established by Freud ${ }^{3,14}$ and those who succeeded him, such treatment requires a certain set of skills, a willingness to expand the bounds of the analytic frame, and particular knowledge of the developing brain. The research that will be considered does not replace psychoanalytic technique but rather augments the analysts in depth understanding of the mind-body-connection.

\section{Neuroscience and Brain Development - Astonishing Facts}

For decades medical science accepted as fact that the brain is completely developed by the early age of three. Over the past few decades, that truth has been continuously invalidated. Ever-changing techniques in neuroscience imaging, magnetic resonance studies, research on post-mortem brains, and, technology that measures brain tissue and density, differentiating between grey and white matter, have proven that the brain continues to grow well into the twenties and even into the third decade of life. ${ }^{15-18}$ This information has led researchers to tie adolescent behavior to neurology, rather than solely to the psychological realm.

Most parents recognize and report that at the onset of puberty their formerly cooperative children change into unrecognizable creatures. Their hormones are proliferating. Their bodies are physically altering and their behaviors become unpredictable. From moment to moment, adolescent mood swings can derail previously stable family dynamics. Rage and defiance replace synergy. Sadness and melancholy become prevalent. Raucous laughter, when in the company of peers, seems intolerable to other members of the family, who are excluded from any pleasant emotional experiences with their child/sibling. Anyone who has been in proximity of three or four teenagers on a subway platform has a clear understanding of the behaviors being referred to. One need not be a family member to feel adolescent dissonance. Vacuous, immature behaviors that seem out of character appear at the strangest times, i.e., an hour after shouting several irreverent expletives, a thirteen-year-old (see the case of Betty below) approaches her mother and with a baby-like voice asks, "Mummy can I sit on your lap?" How can these divergent behaviors be explained?

On a psychological level, there is regression during periods of transition and separation. All separations require mobilization of considerable amounts of aggression. Teens are attempting to separate so they can become independent adults. Therefore, reservoirs of aggression bubble to the surface throughout the course of adolescence. ${ }^{19}$ This is necessary for maturity and health. Neuroscience researchers are telling us something more. Erratic mood swings are not simply in the service of aggression. It is true that adolescents are in the process of separating, but their immature brains contribute organically to their strange behaviors.

There is considerably more grey matter in the brain at the inception of puberty then in its aftermath. Grey matter production increases as the cortical areas thicken with proliferation of neuronal connections in the frontal lobes, which reaches its climax by age eleven in girls and twelve for boys. ${ }^{20}$ The only other time there is such a proliferation of grey matter is during the first three years of life. As neurons develop, they build up myelin, white matter. Myelin insulates and increases the speed of transmission of electrical impulses from neuron to neuron. Therefore, the transmission speed of neurons increases after puberty. Executive functioning, decision-making and judgment that take place in the frontal cortex are offset by ongoing changes in the frontal brain once the grey matter has reached its peak. The adolescent brain is a brain in flux. Long periods of pruning are necessary before all of the neuronal networks are functioning optimally. Pruning makes the brain more efficient as it eliminates rarely used connections (Blakemore \& Frith, 2005, Blakemore, 2018). Teenagers have no cognitive understanding of the seismic changes occurring within their bodies but are usually destabilized and terrified by them.

\section{Case example: Betty}

Thirteen-year-old Betty was a straight A student in ninth grade. Her mother reported in the initial consultation that until recently Betty had been a serious, motivated, sweet and cooperative girl. For years she had been the family's illustrious joke teller but now Betty rarely cracked a smile. Every member of the family was suffering indescribable anguish subsequent to Betty's irrational behaviors and dour moods. For example, she described that Betty had spent a Friday night at her friend's house. She had travelled directly from school with her classmate. Her parents had agreed upon this plan 
in advance. The next morning after Betty left the friend's home she realized she had no idea how to get back to her own, in another borough. She was a gifted girl but had not planned a return route nor thought to ask anyone for help. Fortunately, she had the presence of mind to call her mother from the street. As her mother tried to ascertain exactly where Betty was and how she should proceed home, Betty began to berate her mother. The irate teen hung up. Her mom worried for the next ninety minutes until Betty arrived safely home, as she had not answered her mother's frantic calls. When Betty appeared in the doorway, her mother was near tears. Asking how she figured out how to get home, Betty grimaced and said, "I got it." She then jaunted to her room and closed the door. Her mother wondered which one of them was crazy. As incidents like these became more common, Betty's parents sought treatment. There were certainly emotional conflicts at play, but there was also a disturbing disconnect between Betty's judgment and vituperative outbursts of rage. It was as if Betty had lost control over her emotional life, displaying increasingly impaired judgment and losing decision-making ability. Common sense and emotional stability could not be forced upon her, as her parents hoped, but, rather, the treatment had to contain some of the turbulence while nature did its work on her physical brain. As her parents were helped to understand this, they were able to exhibit more patience with her and accept some of her irrational and explosive eruptions as "normal." Of course, there were conflicts to be resolved, but the dramatic shift in Betty's behavior was what brought her into treatment. This is representative of many teenage treatments. Parents cannot comprehend the drastic changes in their adolescent child - the entire family goes crazy.

\section{Adolescence: What is the brain thinking?}

Skills that include planning, goal-directed behaviors, response inhibition, working memory, and attention are functions of the pre-frontal cortex. When in proper attunement this part of the brain helps us to decrease or inhibit action while we evaluate situations, consider alternative responses, select a course of appropriate action, and then execute a plan. Poor or incomplete executive functioning can lead to difficulties that compromise judgment and decision-making. Kanwal ${ }^{21}$ reports there is a large body of current and ongoing neuroscience research that investigates, "the key neural circuits functioning within the constraints of specific computational models involved in decision -making (p.31)." It appears imperative that clinicians understand some of this data when working with teens experiencing diminished, decision-making ability. In a study by Spear published in 2000, she found the three most likely behavioral changes that occur at adolescence are

1) Increased novelty seeking

2) Increased risk taking

\section{3) Asocial affiliation shift toward peer-based interactions}

Adolescents leave the family unit and move out into the world. This transition is problematic for the teen and her parents. The family is shunned and friends are paramount. It appears that a teenager's problems cannot be evaluated in a vacuum separate from the rest of the family. Previously employed common sense and impulse control vanish, narcissism increases, and anger is always simmering. Of course, in their narcissism, teens are not necessarily conscious of each other's feelings either. Social conflicts arise that can seem as devastating as being spurned by a lover. Sexual impulses surface causing confusion fear and action. But now the once loving support offered by family is experienced as alien, so the teen suffers silently alone - or more likely - acts out.

\section{Family humor goes out the window}

Betty, along with many teenagers appeared to lose the ability to joke with her family, while joviality within adolescent peer groups seems to increase, oftentimes to the dismay of the family who once shared in this experience. Brown ${ }^{22}$ describes humor as an essential tool in brain development, "including the capacity for symbol formation, the realization that other people have a separate mind... and an empathic ability to place one's self in another's experience... p. 171." He goes on to describe how the absence of these characteristics in Asperger's children places them in a very "concrete" world. Regarding humor, it would seem that normal adolescent development passes through a similar stage, in relation to the teen's family, from whom they are unwittingly trying to separate. The disappearance of humorous exchanges can appear to the family as an intentional walling off of previously shared libido. Alienation then replaces connection.

\section{What about puberty?}

Puberty is not adolescence. Puberty and adolescence overlap. Puberty is a physiological transformation where hormones and other bodily functions and attributes change whereby a child develops and achieves sexual/reproductive maturity. Adolescence involves the entire transformation from childhood to adulthood and includes puberty. ${ }^{19}$ Dramatic physical changes in the body can be shocking to parents. Parents must face their own feelings watching their young children develop into unfamiliar sexual beings. These noticeable changes are also undermining to the developing adolescent's psychic integrity. ${ }^{23}$

\section{Case example: Deirdre}

Deirdre's mother called to make an appointment because her daughter was cutting. I had seen Deirdre two years earlier for a total of three sessions. At that time, Deirdre reported not wanting to be in treatment, yet I could sense something had been troubling her that she had been unable put into words. This time she and her 
mother returned to my office respectively, like a wounded lamb and a tornado. I met with the mom first. Mrs. B was histrionic, and I remembered how forceful she had been the first time I met her. She described problems her daughter was having at school with classmates. She told me Deirdre needed self- confidence. When asked, Deirdre agreed with everything her mother said. Mrs. B began to cry as she confessed that she had screamed at the girl, "I wish you had never been born," when she was informed of her daughter's cutting by the school guidance counselor the day before this session. Filled with remorse, shame and self-loathing, Mrs. B seemed to be seeking exoneration. She pleaded with me to help her make reparation with her daughter. She also wanted Deirdre to stop cutting and did not want to know that her daughter was dealing with strong homosexual impulses.

Over the next two years Deirdre reported a vitriolic relationship with her mother. Deirdre had a deep need to talk and to be listened to, while she harbored a secret that she was unable to share with her mother. I suspected her mother already knew what Deirdre had readily revealed in treatment - she was attracted to girls. The possibility of homosexuality frightened Deirdre for many reasons, with her mother's reaction being the most terrifying. It was the slow process of verbalizing these fears that encompassed a large portion of her treatment. Unfortunately, Mrs B had little time or interest in meeting with me about her daughter. She had no wish to understand that her daughter's cutting was a common form of adolescent self-soothing and though concerning, was not necessarily suicidal. ${ }^{24}$ Ms B had her own agenda for Deirdre and frequently cancelled parent sessions giving me the idea that I should fix Deirdre without any input from her, beyond her simple directions: I was to restore Deirdre to her pre- adolescent self.

Deirdre continued to report the punitive consequences imposed by her mom, which were utterly ineffective in reigning Deirdre. A rebellious teen and a punitive parent make for a lethal combination. I failed in my attempts to help Mrs. B accept Deirdre's rebellion as a necessary component of her age. Mrs B's resistance to cooperating with her daughter's treatment felt intractable. Eventually Deirdre threatened to run away from home and had to be hospitalized before her mother could begin to address her daughter's sexuality and emotional needs. Deirdre appeared to have found a way to get what she needed from her mom.

\section{Case example: Andrew}

When Andrew first entered treatment, he was fourteen years old. It was the summer before he would enter high school. His parents were worried about his failing grades and his deteriorating relationship with his father, who had just moved out of the family home. As I sat with this group I had the feeling that Andrew was loved, yet he was in an emotional pain that his parents wanted to alleviate in spite of their confusion about how to do so. The par- ents were also embarking on a trial separation in their marriage. Andrew's mom spoke openly and wanted Andrew to find a way to improve his relationship with his father. His dad was quiet and spoke very little. The tension between Andrew and his father was palpable. Andrew was articulate and seemed to be a good candidate for treatment. He was also extremely depressed. He attended sessions regularly and talked about his life at school and at home. He reported how he fought and misbehaved at school, was continually suspended for disrupting classes and was involved in numerous sexual relationships. I frequently had the feeling that Andrew fabricated what he talked about in treatment. One day he came to my office bloodied and distraught. He told me that he and his friends had been jumped outside the school by a group of thugs. I gave him a wet cloth and some water as I wondered, but did not ask, who had really assaulted him. I again doubted the truth of what Andrew reported. Perhaps this was due to a disconnection between his words and his affect. Perhaps what he told me was authentic, or perhaps, he was hiding some disturbing reality. Over time, his depression lifted and his grades improved. For the most part, I simply listened to Andrew. After two years he left treatment when the mother moved him to another city. I never knew whether what he reported to me was real.

\section{Adolescent mood}

Spear ${ }^{25}$ reports on studies that have found that adolescents experience an increase in negative affect and show signs of depressed mood more often than older people, and, furthermore, perceive and expect to experience positive situations as less pleasurable than older or younger individuals. This is profound, in that adolescent depression may be a function of brain changes - neurologically determined - rather than psychologically prescribed. A kind of anhedonia sets in, and in their attempts to lighten these moods, teens engage in "novelty-seeking and risk-taking that includes alcohol and drug use" (p. 72). Adolescents may respond to stress differently than older and younger people. Using electronic diaries and mood monitors, Whalen, et $\mathrm{al}^{26}$ report teens that scored low on externalizing and depression assessments, reported excessive levels of anxiety and feelings about stress. Teenage moods changes become difficult to manage or understand. Stress levels increase and overwhelm them. Parents find their previously stable child behaving in ways that disturb and overwhelm family functioning. Frightened by an onslaught of mood swings, bizarre affects and behaviors, parents frequently become punitive which only serves to exacerbate adolescent rebellion.

\section{Case example: Anthony}

Anthony came into my consultation room with his parents. He had been arrested for spray painting the viaduct of an elevated subway station. After an appearance in family court he was sentenced to community service, which entailed removing the graffiti. He was 
also mandated to begin therapy. His parents reported that he had always been a good son, but they were now afraid he was on the path to delinquency. Anthony was fourteen. He did not think his graffiti was criminal. He believed it was an appropriate art form and could not comprehend that private property was off limits, as a canvas for his creative expressions. Anthony also had considerable rage toward both parents that they were respectively unable to manage. His acting out was part of a systemic emotional crisis. On another level he lacked any awareness between cause and effect. Unconsciously he may have wished to be caught and forced to relinquish his law breaking behavior. This might have been his way of communicating that he wanted to be contained by parents who could not set limits. After being presented by local authorities with the consequences of his actions, he demonstrated a persistent block against understanding that what he had done was both unacceptable and dangerous. For some time, he reported that he continued to spray paint walls around the city. Again, I found myself wondering whether he continued to engage in the behavior, or did he just want me to think so? There was an element of magical thinking in Anthony's conception of the problem, which may have been related to his still undeveloped brain and neuronal circuitry. At other times I wondered if I was helping Anthony become a more successful sociopath, by not pressing him to give up his criminal graffiti art. The neuro-scientific viewpoint helped me to accept where he was. I silently held his perceived reality, while his reported behaviors were explored rather than discouraged. His parents wanted him to concede responsibility for his actions with a maturity that he was not yet capable of. Treatment served as a container and a vehicle for putting some of his thoughts and feelings into words.

Brain development cannot be rushed, which may explain why adolescence is a period of such high risk. The nervous system is working to integrate circuits. Different parts of the brain are not fully connected. Thought processes and reason become unstable. It is thus understandable that teens behave erratically. Molinari ${ }^{27}$ recommends a sense of "liquidity," in the treatment of adolescents. She says, "liquidity... describes both the psychic structure of the teenager and the frame of mind that the therapist should have in therapy with a teenager (p. 197)". Of course, not all adolescent behaviors are designed to torment parents. Without an understanding of the myriad developmental issues of this period, teens and parents can become locked in a vicious negative union. Meadow ${ }^{28}$ describes the negative union as a reliving of helplessness, dependency and a lack of adequate means to process the impulses related to these feelings. It is a reliving of the pain, with only occasional relief through omnipotence. It includes the impressions collected in the body and the sensorium during the first months of life and thereafter (p. 25).

Each stage of development requires regression to earlier stages. As the teen demonstrates more immature levels of functioning (and these levels fluctuate causing further distress and confusion), parents become contaminated by the helplessness, impulsivity and loss of control that adolescence arouses. The feelings of loss and separation, along with the terror that this instills, are set loose upon the unwitting teenager and her unsuspecting family. Lewis ${ }^{29}$ describes how the terror and fear of her childhood experiences repeated until she had a working through transference opportunity in a psychoanalytic classroom setting. Transferences that are laid down with our original objects are repeated throughout our lives unless, and until we can resolve them. The work of treating teens is largely to contain destructive impulsivity in the adolescent and contain, while educating parents that, punitive actions designed to reduce their child's crazy behaviors have the opposite effect.

\section{Teens, Substances and Dangerous Behaviors}

If a teen uses marajuana on Saturday, unlike his adult counterparts, the effects of this drug on the hippocampus, and his memory are still powerfully manifesting on Thursday during his chemistry exam. ${ }^{30}$ Studies suggest, although still inconclusively, that alcohol consumption in adolescence may lay down a blue print for future alcohol consumption patterns. ${ }^{31,32}$ In other words adolescent drinking may be linked to future adult drinking problems. Many studies of adolescents and other mammals of adolescent age support the idea that teenage brains process alcohol and cannabis very differently than adults. Teens can experience insensitivity to both substances. A fifteen-year-old who has consumed 5 drinks may not appear to be intoxicated. If she continues to drink, she may end up in the ER with alcohol poisoning, having experienced no warning signs. Alcohol in the teen system can cause memory disruptions that last longer than for adults. ${ }^{25}$ Optimally, it seems that teens should never consume alcohol because they are simply ill equipped to metabolize and regulate its effect.

Teenagers are four times more likely than older drivers to be in a car crash and three times more likely to die in one. ${ }^{33}$ A graduated driver's license, proposed by Herbert and his colleagues, which limits and slowly introduces full freedom of the road, might save teen lives. Driving and the decision-making that new drivers face are multifaceted and should perhaps be introduced gradually (e.g., driving for a limited number of daylight hours during the first six months of gaining a license; driving with an adult in the car; driving with only one other passenger).

The various ways in which adolescents can find trouble appear endless. It is clear that the adolescent brain is one in transition, leaving this population vulnerable and functioning at very high behavioral and psychological risk. The onset of the most severe form of mental illness - schizophrenia - typically occurs in the late teens or early twenties. Spotnitz ${ }^{8}$ suggests there is a pre-disposition for such illness, and yet another thing that can go wrong during this 
precarious developmental stage. The treatment ${ }^{8,9}$ of adolescents has to consider the effects of ongoing brain development as a factor in teenage emotional life.

From what parents report in my consulting room, most teenagers appear unpredictable and court various levels of risk. Rebellion is required in order to reach maturity and separate on their journey to the next level of development - adulthood. Neuroscience has provided data that can supplement our understanding of adolescence. Ongoing adolescent brain development contextualizes a great deal of poor decision-making and suggests teenage behaviors can be effectively beyond their control. Treatment, at a minimum can provide a safe holding environment for teens and their families.

The crux of treatment is to provide emotional containment for teens and their parents. Providing a holding environment for the entire family is the quintessential, ongoing intervention. Regular clinical supervision is a given. My belief is the neuroscience data presented in this paper might offer substantial containment and relief for the clinician, who can lose sight of their own regression and pull to action with such cases, while it advances the collaboration between the two domains treating the same malady. ${ }^{1}$ And in many instances, gently delivered information about teen brain development can ease parental terror, while they experience their child's developmental maelstrom. Scientific data describing teen behaviors, in relation to brain development may provide another layer of rationality, in the presence of adolescent madness.

\section{Acknowledgments}

None.

\section{Funding}

None.

\section{Conflicts of Interest}

Author declares that there is no conflict of interest.

\section{References}

1. Zellner M, Olds D. Building bridges between psychoanalysis and the neurosciences: Insights into decision-making, working memory, repression, autism spectrum disorder, and more. Neuro-Psychoanalysis. 2016;18(1):1-2.

2. Volkow ND, Koob GF. This study could unlock the mysteries of teen brain development. STAT. 2017.

3. Freud S. Analysis of a phobia in a five-year-old boy. Standard Edition. London: Hogarth Press, 1909:1-149.

4. Klein M. The development of a child. The writings of Melanie Klein. $1^{\text {st }}$ Vol. New York: Dell.

5. Freud A, Burlingham D. Infants without families. New York: International Universities Pres; 1944.

6. Aichhorn A. Wayward youth. New York: Viking Press. 1963.

7. Kirman W. Modern Psychoanalysis in the Schools. Wayne, NJ: Avery Publishing Group; 1977.
8. Spotnitz H. Modern psychoanalysis of the schizophrenic patient. New York: Human Sciences Press, 1985.

9. Spotnitz H, Feldman Y, Nagleberg L. The treatment of a pre-schizophrenic adolescent, Modern Psychoanalysis. 1988;13:3-206.

10. Marshall RJ. Mother and child as therapists to each other: A psychoanalytic version of filial therapy. Modern Psychoanalysis. 1993;18:143155.

11. Rosenthal L. The case of Henry, Modern Psychoanalysis. 1999;24:4143.

12. Giedd J. EDinformatics, The Adolescent Brain - Why teenagers think and act differently. 2014.

13. Giedd J. The amazing teen brain. Scientific American. 2015.

14. Freud S. From the history of an infantile neurosis, Standard Edition, London: Hogarth Press, 1918;17:3-123.

15. Spinks S. FRONTLINE Inside the teenage brain. Canada: Public Broadcasting Service. Episode 11, 2002.

16. Blakemore SJ, Frith U. The learning brain. UK: Blackwell Publishing. 2005.

17. Lebel C, Beaulieu C. Longitudinal development of human brain wiring continues from childhood into adulthood. J Neurosci. 2011;31(30):10937-10947.

18. Blakemore SJ. Inventing ourselves: The secret life of the teenage brain. USA: Hachette Book Group. 2018.

19. Lidz T. Adolescence. The person: His development throughout the life cycle. New York, Basic Books; 1968. p. 306-375.

20. Johnson SB, Blum RW, Giedd JN. Adolescent maturity and the brain: the promise and pitfalls of neuroscience research in adolescent health policy. J Adolesc Health. 2009;45(3):216-221.

21. Kanwal GS. Perspectives on decision-making: Implications for understanding psychopathology in psychiatric and psychoanalytic practice. Neuro-Psychoanalysis. 2016;18(1):31-43.

22. Brown LJ. Autistic transformations II: The capacity to tell a joke reflections from work with Asperger's children, Transformational processes in clinical psychoanalysis. New York: Routledge, 2019; pp. 171-188.

23. Colarusso CA. The development of time sense in adolescence. The Psychoanalytic Study of the Child. 1988;43(1):179-197.

24. Feinstein S. Inside the teenage brain: Parenting a work in progress. Latham / New York: Rowman \& Littlefield. 2009.

25. Spear LP. The adolescent brain and the college drinker: Biological basis of propensity to use and misuse alcohol. Journal for the Study of Alcohol Supplement No. 2002;14:71-81.

26. Whalen CK, Jamner LD, Henker B, et al. Smoking and moods in adolescents with depressive and aggressive dispositions: Evidence from surveys and electronic diaries. Health Psychology. 2001;20(2):99-111.

27. Molinari E. Variations on a theme: Child and adolescent analysis. Ferro A editors. Contemporary Bionian theory and technique in psychoanalysis, New York: Routledge; 2018. p. 176-216.

28. Meadow P. The negative union. Modern Psychoanalysis. 1992;17:2333.

29. Lewis MC The "good enough" daughter. Modern Psychoanalysis. 2017;41(1):3-11.

30. Ruder DB. The teen brain. Harvard Magazine. 2008.

31. Spear LP. The adolescent brain and age-related behavioral manifestations. Neuroscience BioBehavioral Review. 2000;24(4):417-463. 
32. Landin JD, Gore Langton JK, Varlinskaya EI, et al. General Anesthetic Exposure During Early Adolescence Persistently Alters Ethanol Responses. Alcohol Clin Exp Res. 2020;44(3):611-619.
33. Herbert W. The teenage brain: How do we measure maturity? Huff Post SCIENCE. 2014 